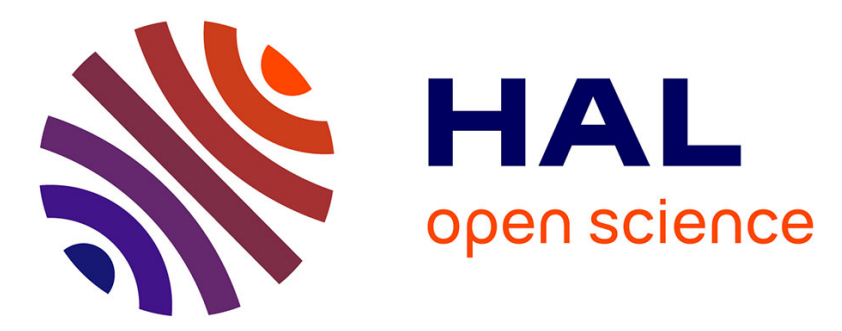

\title{
Investigating the impact of soil moisture on European summer climate in ensemble numerical experiments
}

Constantin Ardilouze, Lauriane Batté, Michel Déqué, Erik van Meijgaard, Bart van den Hurk

\section{- To cite this version:}

Constantin Ardilouze, Lauriane Batté, Michel Déqué, Erik van Meijgaard, Bart van den Hurk. Investigating the impact of soil moisture on European summer climate in ensemble numerical experiments. Climate Dynamics, 2019, 52 (7-8), pp.4011-4026. 10.1007/s00382-018-4358-1 • meteo-03526427

\section{HAL Id: meteo-03526427}

https://hal-meteofrance.archives-ouvertes.fr/meteo-03526427

Submitted on 14 Jan 2022

HAL is a multi-disciplinary open access archive for the deposit and dissemination of scientific research documents, whether they are published or not. The documents may come from teaching and research institutions in France or abroad, or from public or private research centers.
L'archive ouverte pluridisciplinaire HAL, est destinée au dépôt et à la diffusion de documents scientifiques de niveau recherche, publiés ou non, émanant des établissements d'enseignement et de recherche français ou étrangers, des laboratoires publics ou privés. 


\title{
Investigating the impact of soil moisture on European summer climate in ensemble numerical experiments
}

\author{
Constantin Ardilouze · Lauriane Batté · Michel \\ Déqué · Erik van Meijgaard · Bart van den \\ Hurk
}

Received: date / Accepted: date

\begin{abstract}
A better anticipation of high-impact heat and drought on human activity is the underlying motivation of many climate studies focused on the summer season. Although a large body of research has already highlighted the prominent impact of soil moisture anomalies on summer mid-latitudes climate variability and predictability, it still leaves room for a wide range of uncertainty and sometimes contradictions. The present work aims at revisiting soil moisture sensitivity studies by comparing an idealized ensemble model experiment in which soil moisture conditions are prescribed with a reference experiment in which soil moisture evolves freely. Two regional climate models centered over Europe contribute to these experiments and generate very similar results. Simulations with constrained soil moisture display significantly increased correlation between observed and simulated seasonal anomalies of maximum temperature, precipitation and surface solar radiation, as compared to the reference experiment. This widespread increase is not restricted to regions already known as hot-spots of land-atmosphere coupling such as southern Europe, where evapotranspiration is mainly driven by soil moisture. In spite of a limited change in the ensemble spread, the sensitivity experiments show a substantially modified magnitude of temperature and precipitation variability. A focus on two case studies reveal contrasting results for the 2003 and 2010 heat waves. These results stress the prominent role of soil moisture as a boundary condition of the climate system in Europe, including regions that have not been highlighted by previous sensitivity works.
\end{abstract}

Keywords Summer climate variability Soil moisture $\cdot$ Regional Climate modelling $\cdot$ Land-atmosphere coupling $\cdot$ Ensembles

\section{Ardilouze}

CNRM UMR 3589, Météo-France/CNRS, Toulouse, France

Tel.: +33-561-079912

E-mail: constantin.ardilouze@meteo.fr

L. Batté · M. Déqué

CNRM UMR 3589, Météo-France/CNRS, Toulouse, France

E. van Meijgaard · B. van den Hurk

Royal Netherlands Meteorological Institute (KNMI), De Bilt, Netherlands 


\section{Introduction}

A wide range of human activities in mid-latitude regions are specifically affected by summer climate, e.g. crop management and harvesting, energy supply, tourism, or heat-related health issues (Field and Barros, 2014). Global warming is expected to increase the frequency and amplitude of extreme summer events like heat waves and droughts, prone to impact these activities (Roudier et al, 2016; Vautard et al, 2014). The need for improved anticipation and preparedness emphasizes the expectations on the quality and usefulness of summer seasonal forecasts (Buontempo et al, 2014). Summer is characterized by a weaker atmospheric variability than winter, which favors local drivers of predictability (Doblas-Reyes et al, 2000), such as the land component of the climate system, and in particular soil moisture. However, predictability studies focusing on soil moisture initialization have led to contrasting results over Europe when considering either sub-seasonal (van den Hurk et al, 2012) or seasonal time-scales (Ardilouze et al, 2017). In the latter case, an improved soil moisture initialization in spring conveys a robust increase of temperature prediction skill in the subsequent summer over Southeast Europe. An increase is also seen over other regions such as Scandinavia and Eastern Europe, although to a lesser extent. Similar results are found when refining the land surface scheme of the forecast system (Bunzel et al, 2018).

These findings only partially fulfill expectations derived from investigations relating soil moisture and summer climate variability. The physical rationale relies on the influence of soil moisture on the exchange of energy and water from the surface to the bottom layers of the atmosphere through evapotranspiration. For a noticeable impact on climate inter-annual variability, and hence potential predictability, the soil water content must be abundant enough, but also highly variable from one year to another (Orth and Seneviratne, 2017). In addition, soil moisture anomalies must be persistent enough to impact the atmosphere at the seasonal scale (e.g. Seneviratne and Koster (2012)). These conditions are fulfilled in so called "transitional regions" between arid and wet climates. Quesada et al (2012) and Mueller and Seneviratne (2012) showed observational evidence of spring soil moisture anomalies pre-conditioning subsequent summer hot days.

Several studies have contributed to identify those regions where soil moisture can modulate the surface climate in boreal summer. The first initiative based on multiple dynamical models to characterize these regions was the Global Land-Atmosphere Coupling Experiment (GLACE, Koster et al (2004)). Since then, and despite differences due to methodology or model response, further studies on land-atmosphere interactions have agreed on a number of coupling hot-spots. Over boreal mid-latitudes, the US Great Plains and Mediterranean Europe have been identified as such (Seneviratne et al, 2006; Dirmeyer, 2011). At the regional scale, the EURO-CORDEX multimodel evaluation from Knist et al (2017) confirms southern (northern) Europe as a strong (weak) land-atmosphere coupling region in summer over recent years. In that study, the coupling strength is assessed through correlation between variables connected to surface exchange processes and compared to references from station observations and gridded reanalysis. The transitional zone between strong and weak 
coupling across Central Europe is only roughly defined due to inter-model spread and observational uncertainties.

Soil moisture deficit also plays a role in the amplification and persistence of extreme heat waves, in particular those of Western Europe in 2003 (Fischer et al, 2007; Weisheimer et al, 2011) and Russia in 2010 (Miralles et al, 2014). The physical processes at play in linking spring drought to summer hot days over Europe are described in Zampieri et al (2009) and Quesada et al (2012). Once heat waves have settled, enhanced sensible heat originating from dried-out soils exerts a positive amplification feedback. Although Western Europe and Russia are not considered as hot-spots, predictability studies such as Prodhomme et al (2016) have shown that an accurate soil moisture initialization was needed to correctly capture heat wave events such as the Russian summer of 2010

The sensitivity of European summer climate inter-annual variability to soil moisture is therefore incompletely understood and related studies usually fall into one of the two following categories. On the one hand, predictability studies help exploring the actual prediction skill of coupled forecast systems associated to land surface initialization, but they cannot bring much information on the sensitivity of climate variability to the soil moisture component throughout the integration of the ensemble simulations. On the other hand, model sensitivity studies usually rely on a model single long-term integration for which years cannot be compared individually to observations. Combining both approaches can help bridging the gap between predictability studies relying on initial conditions and sensitivity studies focusing on land-atmosphere coupling and seasonal variability. Here, we study the capacity of climate model simulations to reproduce observed atmospheric inter-annual anomalies when soil moisture is ideally constrained compared to simulations when soil moisture is only prescribed at initialization. In the approach we have chosen, both sets of simulations consist of an ensemble of summer season simulations initialized by the same pseudo-observed soil water content, but in one case the simulated soil moisture evolves freely afterwards while in the other case, it is constrained towards pseudo-observations throughout the course of the model integration. Such an idealized set-up is inspired by the experimental framework applied in the PROVOST project (Palmer et al, 2000), in which sea surface temperature was prescribed instead of soil moisture. The comparison focuses on the model accuracy to reproduce the observed inter-annual variability and their ability to capture two extreme summers. The experiments have been performed with regional climate models (RCMs) in order to benefit from more detailed surface characteristics and a better simulation of extremes than coarser global models (Flato et al, 2013). Two distinct RCMs contribute to this study to better assess the model-dependence of our results.

The paper is structured as follows: section 2 describes in more detail the experimental set-up, the observational reference datasets and the model evaluation metrics. Results are commented in section 3. Finally, section 4 summarizes the main conclusions and discusses limitations and perspectives to this study. 


\section{Experiments and data}

\subsection{RCMs and dynamical downscaling}

The experimental setup is based on the dynamical downscaling of an ensemble of seasonal-scale simulations initially performed with General Circulation Models (GCMs) on a coarse global grid. These global simulations provide lateral boundary conditions to RCMs over a high resolution $\left(0.22^{\circ}\right)$ domain covering Europe. The nested experiments are carried out with either interactive (-REF hereafter) or prescribed (SOIL hereafter) soil moisture over the high-resolution domain. More specifically, two RCMs contributed to this study: RACMO 2.2 (Van Meijgaard et al, 2012), carrying HTESSEL as land surface scheme (Balsamo et al, 2009) and a version of ALADINCLIMAT 5 (Colin et al, 2010) with a refined land surface scheme (SURFEX 7.2 (Masson et al, 2013) including a multi-layer soil diffusion scheme (Decharme et al, 2011)). The common spatial domain is EURO-CORDEX EUR-22 (boundaries: 27N $72 \mathrm{~N}, \sim 22 \mathrm{~W} 45 \mathrm{E}$, spatial resolution: $0.22^{\circ}$ ). The experiments are listed in Table 1. For compatibility reasons, the lateral boundary conditions are different for each RCM. They are provided by two forcing GCMs, namely EC-Earth 3.1 (Hazeleger et al, 2010) for RACMO and CNRM-CM (Voldoire et al, 2013) for ALADIN. All experiments consist of 15-member ensembles of 20-year summer season simulations initialized on May 1st and spanning the 4 months from May to August 1993 to 2012. The main characteristics of the forcing global simulations are reported in Table 2. The ensemble spread originates solely from these global simulations. Note that the RACMO reference experiment (here R-REF) along with its forcing GCM simulation are also used and further described in Manzanas et al (2017). Additional details on the CNRM-CM seasonal forecast system used to generate ALADIN lateral boundary conditions are provided in Batté et al (2018).

\subsection{Soil moisture reference and prescribing techniques}

Because of too scarce or superficial observations, global soil moisture estimates are often derived from land surface model (LSM) reconstructions. Various datasets result from offline LSM runs constrained by atmospheric reanalysis forcing (e.g. Sheffield and Wood (2007), Reichle et al (2011)). ERA-Interim/Land (Balsamo et al, 2015) (hereafter denoted as ERA-Land) is a reconstruction based on the HTESSEL LSM (Balsamo et al, 2009; Albergel et al, 2012) forced by atmospheric input derived from the ERA-Interim reanalysis (Dee et al, 2011) with corrected precipitation. In spite of not assimilating observed data, the fair results of ERA-Land verification against observations justify its use as a reference for soil water content estimates. Here, ERALand is used to prescribe soil moisture in the dedicated RCM experiments, namely R-SOIL and A-SOIL. It is also used to initialize the land surface component in the GCM simulations that provide forcing boundary conditions to the four RCM experiments. As can be seen from Table 2 summarizing GCM forcing experiments, the CNRM-CM land component differs from that of ERA-Land. To perform the initialization of land surface from ERA-Land, an interpolation based on a transfer function 
is applied (Boisserie et al, 2016). Another possibility would have been to retrieve initial conditions for the land surface from an offline simulation of the SURFEX LSM. Here, we choose to use the same dataset to initialize both GCMs so as to limit discrepancies in the experimental design.

ERA-Land was also used to constrain soil moisture in the RCM experiments with ALADIN and RACMO (A-SOIL and R-SOIL, respectively, see Table 1). Although RACMO and ERA-Land share the same underlying LSM, the difference in spatial resolution implies that one ERA-Land grid cell, corresponding to one soil type, matches multiple RACMO grid cells potentially differing in terms of soil type and thus hydrological properties. Thus, the transfer from ERA-Land to RACMO is performed by interpolating a soil moisture index (SMI). It is computed following Equation 1, where $\theta$ is the volumetric soil water content, $\theta_{\mathrm{wp}}$ the wilting point of the considered soil layer and $\theta_{\mathrm{fc}}$ the field capacity.

$$
S M I=\frac{\theta-\theta_{w p}}{\theta_{f c}-\theta_{w p}}
$$

SMI is then converted back into water content in the target grid, taking into account the soil type attributed to each cell. These retrieved water content values replace simulated water content prognostic fields during the RCM integration once a day at 00Z. In the case of ALADIN, ERA-Land soil water content is interpolated onto the SURFEX grid using the aforementionned transfer function, also based on SMI regridding. Then, at each time step of the model integration, simulated soil moisture fields are strongly nudged (Douville, 2003; Douville et al, 2016) towards those derived from the interpolated ERA-Land data of the corresponding day. If we call $X$ the soil water content prognostic variable of a considered soil layer, then the temporal evolution of $X$ in A-SOIL follows the nudging Equation 2, where $M(X)$ is the tendency term for $X, \sigma$ is a vertical profile factor comprised between 0 and $1, X^{\text {ref }}$ the reference soil water value derived from ERA-Land, and $\tau$ a characteristic relaxation time. Here, $\sigma$ was set to 1 and $\tau$ to 24 hours for every soil layer. We justify this a priori choice of relaxation time by the need for a strong nudging of soil moisture to stay close to the R-SOIL set-up. This is the case when the soil water content characteristic time is close to or greater than one day. We infer that only the superficial layer water content evolves at a faster pace than one day. There, our nudging remains loose but the memory of superficial moisture anomalies is negligible at seasonal time scales. Furthermore, applying a sub-daily nudging would require to carry out a dedicated time interpolation of ERA-Land daily data, hence introducing a new source of uncertainty.

$$
\frac{\partial X}{\partial t}=M(X)+\sigma \cdot \frac{X^{r e f}-X}{\tau}
$$

Note that for R-SOIL and A-SOIL, the method used to prescribe soil moisture has been applied similarly to the 15 ensemble members. The ensemble spread results from perturbations in the atmospheric component in the forcing GCMs. As an illustration of the nudging technique, Figure 1 compares A-REF and A-SOIL spread for superficial volumetric soil water content over FR for a randomly selected year (1998) 
where the box and whiskers depict the day-to-day intra-ensemble spread in ALADIN experiments.

Soil moisture-related metrics should focus on the amount of soil water content prone to impact climate at the seasonal scale. We therefore use SMI as previously described, computed over the root-zone only. This fraction of soil water available for evapotranspiration is commonly used in climate studies considering land-atmosphere coupling (e.g. Betts (2004)) or to retrieve comparable soil moisture between different LSMs that do not share the same soil parametrization and discretization (e.g. Boisserie et al (2016); Douville (2003)).

The characteristics of the models led us to use two slightly different techniques to constrain soil moisture, as described above. However, since both R-SOIL and ASOIL soil water contents have been guided towards the same reference data, they should be almost perfectly correlated to each other. This is verified in supplementary Figure S.1 where, as expected, these correlations are close to 1 between A-SOIL and $\mathrm{R}$-SOIL experiments over the whole domain. One remarkable exception is northern Finland. This is the only region where A-SOIL SMI is not correlated to ERA-Land in spite of the nudging (not shown). This discrepancy is due to abundant soil water content with a relatively low inter-annual variability in this region, characterized by organic soils in ERA-Land. After nudging, the soil water content in ALADIN remains well below that of ERA-Land, probably reaching a saturation threshold, which prevents the inter-annual variability signal to be properly conveyed from ERA-Land to ALADIN. Overall, since A-SOIL and R-SOIL have an almost identical soil moisture inter-annual variability, we conclude that the different approaches to constrain their soil moisture do not hamper the inter-model comparison.

\subsection{Atmospheric reference data and evaluation metrics}

By design, models represent climate dynamics and processes in an incomplete way. Consequently, they produce systematic errors leading to a biased simulated climate with respect to observations. A straightforward and commonly-used method to remove the bias in climate predictions is to consider observed and simulated anomalies relative to their respective climatologies for a given verifying time. The assessment carried out in this study relies on this approach. The anomalies are seasonally averaged over boreal summer, i.e. the 3-month June to August (hereafter JJA) period.

Three focus regions are defined, over France (hereafter FR), Sweden (SW) and a region straddling Ukraine and Russia (RU). They are depicted on Figure 2 and their boundary coordinates are reported in supplementary Table S.1. All three have very distinct climate features : mainly ocean temperate for FR, continental with warm summers for RU and continental with cool summers for SW. RU and FR have also been selected for a specific analysis of extreme summers during the full simulation period (respectively 2010 and 2003).

The reference observed daily precipitation, minimum temperature (Tmin) and maximum temperature (Tmax) at screen level are taken from EOBS v.14 European gridded data set at $0.25^{\circ}$ (Haylock et al, 2008). Local station observational data of monthly downward surface shortwave radiation (DSSR) are derived from the Global 
Energy Balance Archive (GEBA) (Sanchez-Lorenzo et al, 2015). Neither EOBS nor GEBA is a reanalysis stricto sensu, meaning that they are completely independent from any model physical parametrization.

The first part of section 3 presents a deterministic assessment of the experiments. This implies that the metrics are only based on their ensemble mean. It relies mainly on Pearson correlation over time of grid point or area-averaged variables, and mean square errors. The statistical significance is derived from $95 \%$ confidence intervals, computed after a Fisher z-transformation of the correlation coefficient, or after the method by Zou (2007) in the case of correlation difference. The latter is recommended by Siegert et al (2017) to detect correlation improvements.

The probabilistic evaluation of our experiments allows to extract information given by the ensemble members. In particular, the second part of section 3 details the impact of the experimental set-up on the ensemble spread, followed by an analysis of variance for Tmax and precipitation over the three focus regions.

\section{Results}

\subsection{Ensemble mean evaluation}

\subsubsection{Inter-annual variability over the simulation period}

Before verifying the capacity of the models to capture inter-annual climate anomalies related to a boundary condition such as soil moisture, we first need to assess how well soil moisture inter-annual variability is simulated in the unconstrained simulations. This is achieved by computing SMI JJA correlations to ERA-Land for both reference experiments R-REF and A-REF. Figure 3 shows that these initialized experiments manage to significantly capture the inter-annual sign of soil moisture anomalies over less than $2 / 3$ of grid points. The only common regions with a fair signal are Iberia and a strip extending from southern Germany to the Black Sea. SMI correlations are irrelevant, and therefore masked out, in desert regions of North Africa and the Middle East where the soil water content is very small. In addition to correlation, the memory of soil moisture, i.e. the degree of persistence of spring anomalies throughout summer, is assessed over the three focus regions described in section 2.3 (Fig. 4). Unlike A-REF, a fair agreement is found between R-REF and ERA-Land over RU (long-lived soil moisture memory) and SW (short-lived soil moisture memory). It is likely that R-REF and ERA-Land are better matches since both datasets are based on the same LSM. However, A-REF SMI memory is closer to ERA-Land than R-REF over FR (intermediate memory), suggesting that memory is not exclusively determined by the LSM formulation. The sharp drop in correlation during the first days for A-REF over the three regions may result from an initialization shock triggered by the difference between ALADIN and ERA-Land surface schemes. The diversity of models response to soil moisture initialization, together with the uncertain representation of reality by ERA-Land as a model-dependant reference are challenging aspects when considering the contribution of soil moisture to climate inter-annual variability. However, they confirm a priori the added value of comparing two mod- 
els in this study. Furthermore, forcing soil moisture towards the same reconstructed values in both models allows to obtain two sets of idealized atmospheric simulations with a common 'perfect' evolution of soil moisture as a boundary condition.

Daytime surface turbulent heat fluxes balance the major part of incoming energy from solar radiation. Consequently, evapotranspiration has a pronounced diurnal cycle (Novick et al, 2009) and reaches a minimum during nighttime, in the absence of incoming shortwave radiation. Furthermore, Tolk et al (2006) showed that in a semi-arid environment, virtually all the nighttime fraction of evapotranspiration is prescribed by atmospheric conditions. Thus, in regions where soil moisture is considered a major driver of evapotranspiration, we can infer that the coupling between soil moisture and the boundary layer gets cut-off at night. Based on that assumption, we assess separately the sensitivity of Tmin and Tmax seasonal anomalies to soil moisture, the former value being generally reached at the end of the night. Time correlations for Tmin (Fig. 5) show little difference between SOIL and REF experiments for both models, except a substantial gain over the easternmost part of the domain for R-SOIL (Fig. 5(c)). Conversely, prescribing soil moisture brings a spectacular increase in correlation for Tmax (Fig. 6) for both models, over almost the whole domain. The only regions exhibiting limited signal in SOIL experiments are roughly patches of North-West Europe and Poland for RACMO and most of the Alps for ALADIN. This overall improvement was expected for southern Europe, where soil moisture is the main driver of evapotranspiration. For the other regions where Tmax variability benefits from improved soil moisture, we hypothesize that the other terms of the surface energy budget play a prevailing role. Since water content impacts the soil heat capacity, it is likely that the SOIL experiments have more realistic interannual variability of both ground heat fluxes and sensible heat fluxes. Verifying this against observation is very challenging because of the lack of reliable observations and the model-dependent parametrization of turbulent fluxes. However, the compared correlations of these fluxes between models (supplementary Fig. S.2 and S.3) shows consistent inter-annual variability in both SOIL experiments, even at higher latitudes. Additionally, over Northeast Europe, SOIL experiments are better correlated for sensible than for latent heat fluxes.

Another noticeable feature is the relative match for each REF experiment between the regions with SMI and Tmax significant correlation (Fig.3(a) and 6(a), 3(b) and 6(c)). Even if correlations do not give insight on causal relationship, this result is consistent with a strong link existing between soil moisture and temperature interannual variability over Europe in summer.

Since improved soil moisture variability affects Tmax, it may also impact the convective boundary layer and diurnal cloud development. We use observed incoming solar radiation variability as a proxy to verify this hypothesis. Time correlation for DSSR between in-situ observations at GEBA stations and simulations at the corresponding grid point are reported on Figure 7. SOIL experiments show either higher or unchanged correlations as compared to REF. The correlation increase concerns mainly Northeastern-most locations, but also central Europe for R-SOIL. Hence, over these regions, seasonal soil moisture anomalies likely drive cloud cover anomalies to a certain extent, even if the processes involved cannot be clearly identified from our study. Based on our results on turbulent fluxes, we can only hypothesize 
that soil moisture anomalies mainly impact sensible heat fluxes which in turn influence the diurnal boundary layer development and ultimately cloud evolution. A dedicated process-oriented experiment would be required to specify the underlying mechanisms.

It is well known that the precipitation skill of seasonal forecast systems is very limited over Europe (Rodwell and Doblas-Reyes, 2006). This is also the case in our REF experiments despite dynamical downscaling (Fig. 8 (a) and (c)). However the idealized framework of SOIL experiments leads to a strong increase in precipitation correlation for both models (Fig. 8 (b) and (d)). It should be noted that the regions benefiting from this improvement are not restricted to southern Europe, usually pinpointed as a hotspot of land-atmosphere coupling. Here again, models partly agree on the regions with increased correlation, but most of the areas covered by our three subdomains of interest, namely FR, RU and SW, are concerned. The root mean square error of precipitation anomalies is also reduced overall in SOIL experiments as compared to REF, although this reduction is hardly significant (supplementary Fig. S.4).

\subsubsection{Seasonal bias}

The Tmax summer temperature bias is shown in Figure 9. The slight cold bias present over the vast majority of the domain in REF for both models is further increased in SOIL experiments, in particular over Eastern Europe and Russia. In the case of ALADIN, the cooling impact of prescribed soil moisture is very likely due to the increase of mean soil water content in the SOIL experiment with respect to REF (not shown). Consequences in terms of temperature variance are discussed in the next section. As for precipitation, (Supplementary Fig. s.5), the simulations with prescribed soil moisture tend to produce more precipitation across the whole domain. Thus, dry biases in REF are reduced in SOIL, but wet biases are amplified. Overall, the mean climate of both models is altered with respect to the reference data when soil moisture is prescribed.

All the results presented so far demonstrate a widespread sensitivity of summer inter-annual variability to soil moisture boundary conditions. Despite a slight degradation of the model mean climate with respect to observations, SOIL experiments better capture the sign of annual anomalies. Beyond consequences on the ensemble mean, we now investigate the impact of soil moisture prescription in a probabilistic framework. To that end, the next section focuses on the sensitivity of the ensemble spread to our experimental design and on the analysis of inter-annual and intra-annual variance.

\subsection{Probabilistic evaluation}

\subsubsection{Regional spread}

The same nudging has been applied across the whole domain for all the ensemble members of SOIL experiments. Consequently, one can expect by design a smaller soil wetness ensemble spread than in REF for which soil moisture is not constrained. 
Figure 1 compares A-REF and A-SOIL spread for superficial volumetric soil water content over FR for a randomly selected year (e.g. 1998) where the box and whiskers depict the day-to-day intra-ensemble spread in ALADIN experiments. This example illustrates the extent to which the soil moisture spread is reduced in the nudged experiment. We generalize this spread evaluation for both models by computing the quadratic mean of the SMI ensemble variance for each day of the 4-month May-toAugust period over the 20-year period (Supplementary Equation S.1). The JJA mean of these daily values is displayed in Table 3 for the three focus regions. For both models, and despite different techniques, soil moisture prescription at a daily frequency leads to a reduction of spread by about $70 \%$, regardless of the considered region. The spread reduction is higher for RACMO than for ALADIN, which is not surprising since the relaxation technique in ALADIN constrains soil moisture more softly than the replacement technique applied in RACMO.

Theoretically, the reduction of spread for soil moisture could translate into a reduction of spread for near-surface climate fields, at least where soil moisture drives the partition of turbulent heat fluxes. These fluxes relate to daytime near-surface temperature but also precipitation through convective boundary layer development. We verify this hypothesis over our 3 focus regions characterized by distinct precipitation regimes in summer. Indeed, the share of convective precipitation in total precipitation is lower over SW (about $50 \%$ according to ERA-Interim) than over FR (approx. $68 \%)$ or RU $(75 \%)$. These estimates are derived from a reanalysis and may thus be inaccurate but they characterize different precipitation regimes over Europe (supplementary Fig. S.6). However, Table 4 shows that the reduction in Tmax spread is small, and generally below $10 \%$. A similar analysis for precipitation and DSSR does not reveal any change in spread (not shown).

In contrast with the previous section highlighting an acute sensitivity of the ensemble mean to soil moisture, these results suggest that in our models, the ensemble spread is barely sensitive to soil moisture over most of Europe.

\subsubsection{Analysis of variance}

The simulations with constrained soil moisture proved to better capture the sign of temperature or precipitation summer inter-annual anomalies. The impact on the variance of these fields can also be assessed fairly robustly thanks to our experimental design based on ensembles. Here we analyze separately the inter-annual and intraannual contributions to the total variance. The intra-annual term is the mean variance of daily values computed separately for each year while the inter-annual one is the variance of seasonally averaged daily values. The decomposition of the variance for a given field $X$ follows Equation 3, where $n_{\mathrm{d}}$ is the number of summer days of each year $y$, i.e. 92 from June 1 st to August 31 st, $N$ is the total number of summer days in the entire period $\left(N=n_{\mathrm{d}} * 20\right)$. The overbar denotes the arithmetic mean.

$$
\begin{aligned}
\operatorname{Var}(X) & =\frac{1}{N} \sum_{i=1}^{N}\left(X_{i}-\bar{X}\right)^{2} \\
& =\frac{1}{N} \sum_{y} \sum_{d=1}^{n_{d}}\left(X_{d}^{(y)}-\overline{X^{(y)}}\right)^{2}+\frac{n_{d}}{N} \sum_{y}\left(\overline{X^{(y)}}-\bar{X}\right)^{2}
\end{aligned}
$$




$$
=\operatorname{Var}_{\text {intra }(y)}(X)+\operatorname{Var}_{\text {inter }(y)}(X)
$$

The decomposition is applied to the observations and to the 15 members of each experiment. This provides samples of 15 ratios $\operatorname{Var}\left(X_{\text {exp }}\right) / \operatorname{Var}\left(X_{\text {obs }}\right)$ per experiment, for each term of the variance decomposition. When comparing experiments, a t-test is performed to verify if variances significantly differ at a 95\% confidence level. Results for the three focus regions are reported in Table 5.

For both temperature and precipitation, the intra-annual term is much greater than the inter-annual one, by a comparable factor for observations and simulations (not shown). This expected feature relates to the greater magnitude of day-to-day variations as compared to that of seasonal ones. Tmax variance terms in SOIL are systematically and significantly reduced over RU and FR with respect to REF. The reduction also applies to SW but without statistical significance in general. In comparison to observations, SOIL experiments show an improvement for FR where the REF experiments overestimate both inter and intra-annual variances. By contrast, the variance terms are deteriorated over RU in SOIL experiments which show an excessively low amplitude. Interestingly, the two variance terms for precipitation evolve oppositely in SOIL experiments (5 (c) and (d)) where the intra-annual variance increases and the inter-annual variance decreases with respect to REF. This tendency is however less pronounced and generally not significant for RACMO.

Hence, the magnitude of inter-annual variability is restrained when soil moisture is prescribed in our experiments. This is likely the consequence of a soil mean state wetter in SOIL than in REF experiments. The underlying mechanism, described in Seneviratne et al (2010) section 7.2, can be described as follows: when soil moisture is abundant enough, it stops being a limiting factor of evapotranspiration. This implies that variations in soil moisture do not translate into variations of surface heat fluxes, and therefore limit temperature and precipitation variability. As for the opposite trend of intra-annual variance between precipitation and temperature, we can hypothesize that wetter soils in SOIL experiments increase the latent heat flux in response to intense solar radiation, which mitigates daily hot temperature extremes and also favors the occurrence of days with convective precipitation.

\subsection{Focus on two extreme summers}

A year-to-year comparison of observed vs. simulated Tmax anomalies averaged over FR and RU is shown in Figure 10. The amplitude of simulated anomalies is damped by the ensemble averaging. Hence, observed anomalies and simulated ensemble mean anomalies are normalized by their respective standard deviation. A similar analysis for precipitation can be found in supplementary Figure S.7. As mentioned in the introduction, the case of 2003 over FR (left-hand column) and 2010 over RU (right-hand column) are worthy of attention since these summers were exceptionally warm and dry in concerned regions. Generally, SOIL outperform REF experiments in capturing a pronounced dry and warm anomaly, except for RACMO in 2003, where R-REF and R-SOIL both succeed in simulating these anomalies. Further insight is provided by means of an index defined as the number of days where Tmax exceeds a given threshold during these particular summers. Instead of using a common absolute temperature 
value as threshold for both observation and simulations, we select relative thresholds computed monthly as the 80th percentile of Tmax distribution of each experiment and observation. This allows a fair comparison, regardless of the models bias and the observational uncertainty. The benefit of prescribing soil moisture is visible for 2010 where unlike REF, both SOIL experiments capture a positive signal correctly located over West Russia (Fig. 11). It should be kept in mind that the difference of amplitude between indices derived from observation and simulations partly results from damping due to ensemble averaging. Conversely, for 2003, despite a weak signal over Italy and the Balkans for RACMO, prescribing soil moisture only leads to small improvements (supplementary Fig. S.8). Interestingly, REF experiments do manage to simulate the observed 2003 negative SMI anomaly over Western Europe but not the one over Russia in 2010 (Fig. 12). For the latter year, SOIL protocol deeply modifies the average soil moisture state, which seems crucial in the development of the heat wave. This result supports the attribution study from Hauser et al (2016), showing that dry soil conditions alone increased the likeliness of occurrence of the 2010 event by a factor of six. For 2003, prescribing soil moisture only slightly modifies the summer-averaged soil moisture content with respect to REF. This is consistent with the limited differences found between the experiments for our heat index. We relate the apparently weak response of the models to the findings from Feudale and Shukla (2011), suggesting that the 2003 heat wave was more related to the global sea surface temperature conditions. Moreover, our index tends to highlight long-lasting warm spells, like that of 2010, as opposed to the 2003 summer heat anomaly, which was characterized by multiple shorter-lived warm spells, including the relatively brief but extremely intense early August episode. Without overlooking the contribution of land surface feedbacks in the summer 2003 extreme heat, as such already identified by e.g. Weisheimer et al (2011), we infer that our simulations miss a key ingredient such as the temporal structure of circulation regimes. This is consistent with the mechanism described in Miralles et al (2014) for mega heat waves, suggesting that atmospheric high pressure blocking anomalies trigger situations favoring clear skies with enhanced evaporative demand, leading to a rapid soil dry-out, which in turn contributes to temperature escalation. Very similar results are found when assessing these two case studies in terms of precipitation deficit, by means of a 3-month Standardized Precipitation Index of these two case studies (not shown). This supports the findings of Schär et al (1999) who pointed out the strong positive dependence of summertime precipitation to soil moisture over large parts of Europe. Underlying processes are less clear than for soil-moisture temperature interplay : the complex and sometimes reverse feedbacks and physical mechanisms involved are still being investigated (Schär et al, 1999; Seneviratne et al, 2010; Guillod et al, 2015).

\section{Conclusions}

This study investigates the sensitivity of inter-annual climate variability to soil moisture in climate models over Europe, based on two sets of modelling experiments. Constraining daily soil moisture towards reconstructed values provides an idealized experiment framework fitted to evaluate the models response with respect to standard 
initialized simulations, in which soil moisture evolves freely. This work relies on two distinct limited area models using boundary forcings from two global initialized simulations carried out by different GCMs. Over large parts of Europe, climate simulations with imposed realistic soil moisture are significantly more accurate in terms of temperature and precipitation inter-annual variability. Models partly disagree with each other on the most sensitive regions but the improvement is not limited to southern or mediterranean Europe, traditionally identified as hot-spots of land-atmosphere coupling. Over northern Europe, the results indicate that realistic soil moisture likely improves land surface temperature, sensible heat flux and convective boundary layer development. The robustness of our results is supported by an overall consistency between the two RCMs. The main conclusion from our study is that soil moisture as a boundary condition plays a major role in controlling the amount of summer climate variability in Europe, including in higher latitude regions where the evapotranspiration is not mainly driven by soil water content. A very similar experiment carried out at the global scale with a GCM but not described here for the sake of clarity, brings similar conclusions for North America and China. However, no impact is found over Indian and African monsoon regions. Our results also support the findings from Mueller and Seneviratne (2012) whose observational study suggests that the extent of regions concerned by strong soil moisture-atmosphere coupling has been underestimated by previous model-only studies. Going a step further could consist in comparing the impact on summer climate of soil moisture inter-annual variability with that of day-to-day variability. Addressing such point would require complementary experiments, e.g. by prescribing a seasonally constant soil moisture anomaly derived from observations for each simulated year.

Our idealized framework does not fit the standard of a potential predictability study since it prevents any feedback from the atmosphere to the soil moisture and it does not address the seasonal predictability of soil moisture itself. However, the results from this study may encourage shaping any future predictability research targeted at making the most out of land surface initialization. In particular, it would be worth assessing the gain of prediction skill resulting from a mitigation of model systematic errors. These errors on rainfall amount and intensity could rapidly alter the information included in land surface initial conditions and thus hinder the prediction skill. To our knowledge, the impact of these biases during the early stage of a forecast system integration has not been thoroughly evaluated, and would deserve a dedicated experiment. Soil moisture might well be an under-tapped source of warm season predictability because of uncertainties inherent to the modelling of the land surface and its complex interactions with the atmosphere.

Acknowledgements This study was supported by the EU-FP7 project SPECS (grant agreement 308378) Bart van den Hurk was supported by the EU-H2020 project IMPREX (grant agreement 641811). We acknowledge the E-OBS dataset from the EU-FP6 project ENSEMBLES (http://ensembles-eu.metoffice.com) and the data providers in the ECA\&D project (http://www.ecad.eu) as well as Martin Wild (Institute for Atmospheric and Climate Science, ETH Zürich, Zürich, Switzerland) for providing the GEBA dataset. 


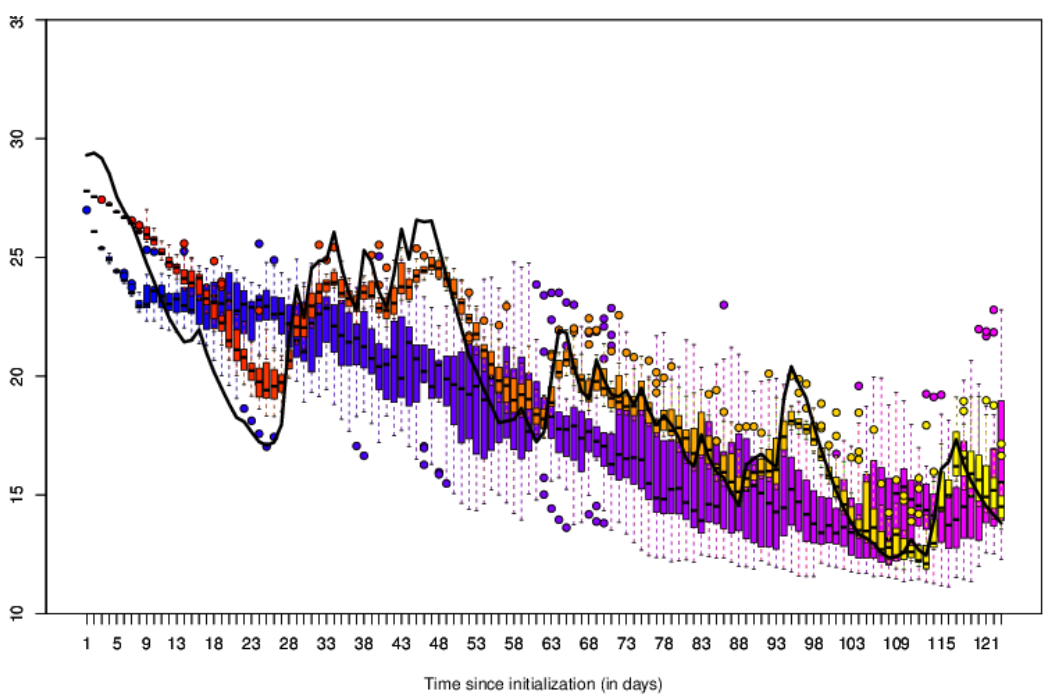

Fig. 1 Daily spread of superficial (seven top centimeters) soil water content in $\mathrm{kg} \cdot \mathrm{m}^{-2}$ from May 1 st to Aug. 31st 1998 over FR for A-REF (cold shades) and A-SOIL (warm shades). The black solid line is the nudging reference value derived from ERA-Land. The whiskers extend to the most extreme data point which is no more than 1.5 times the interquartile range depicted by boxes. Outliers are represented by circles

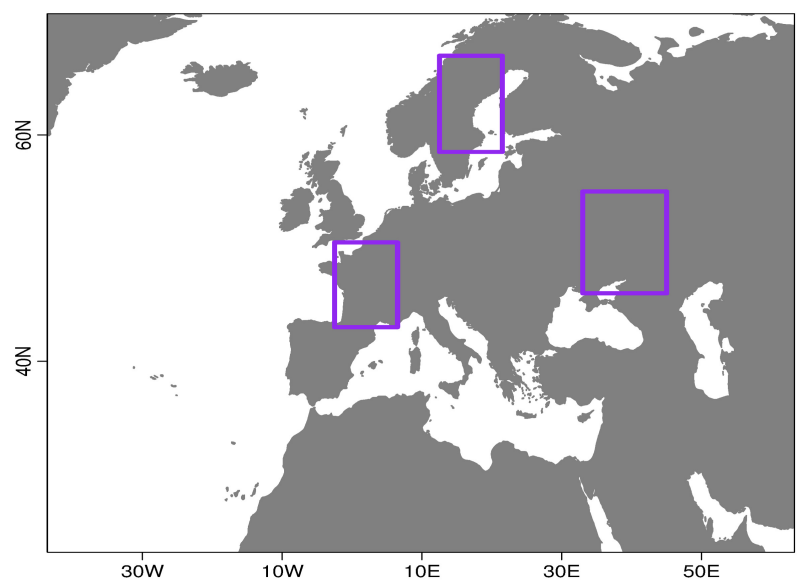

Fig. 2 Spatial extent of focus regions 


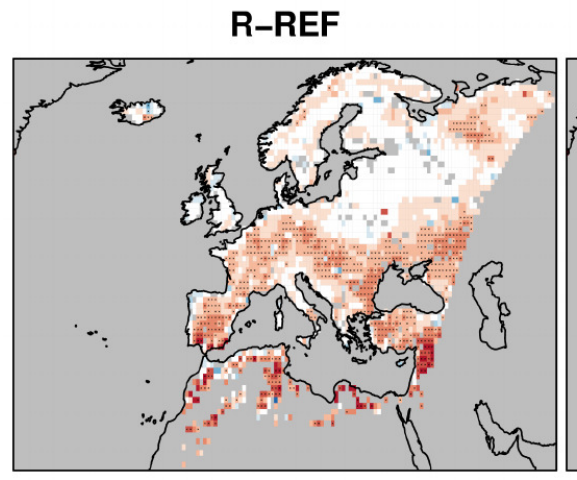

(a)
A-REF

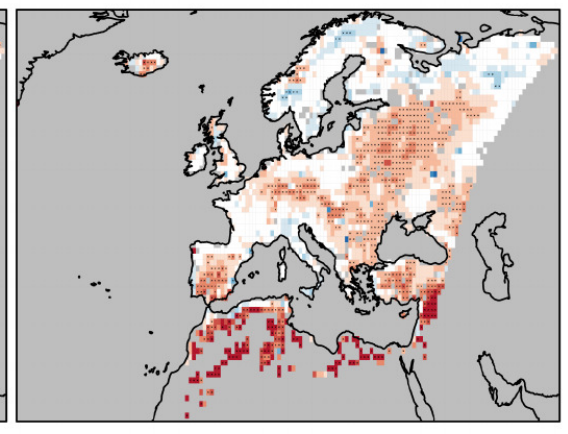

(b)

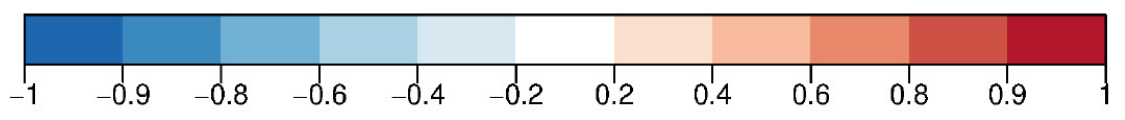

Fig. 3 JJA SMI correlation between ERA-Land and (a) R-REF (b) A-REF. Stippling depicts values significantly different from 0 with a 95\% confidence. Pixels with ERA-Land SMI values below 0.1 have been masked out 
FR

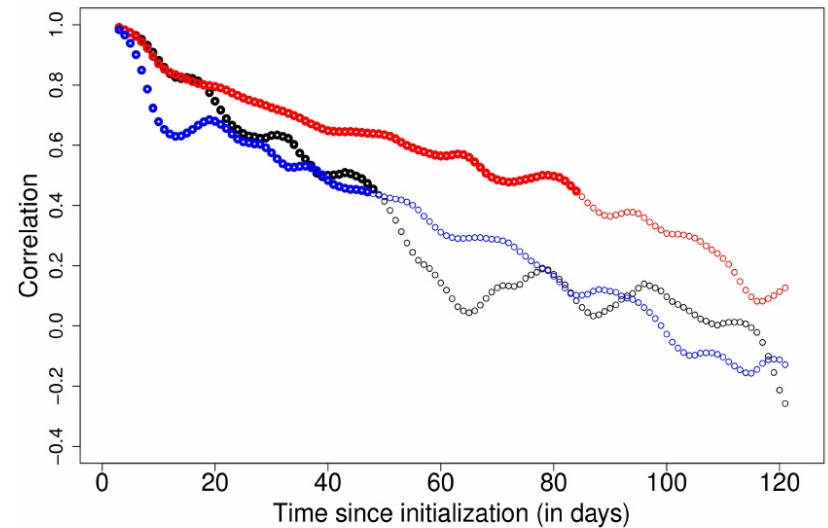

(a)

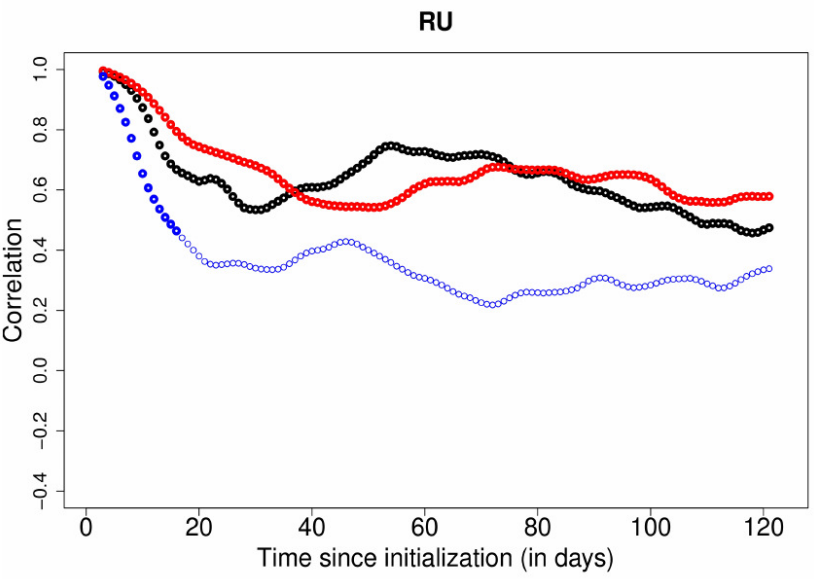

(b)

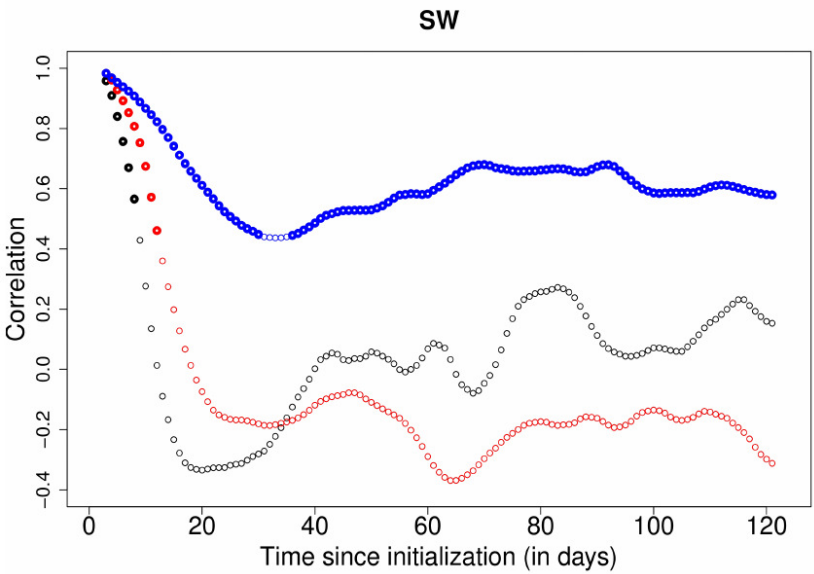

(c)

Fig. 4 Correlation between May 1st SMI and 5-day running mean SMI for ERA-Land (black), A-REF (blue) and R-REF (red) over (a) FR (b) RU and (c) SW. Thick circles mark significant correlations with a $95 \%$ confidence level 


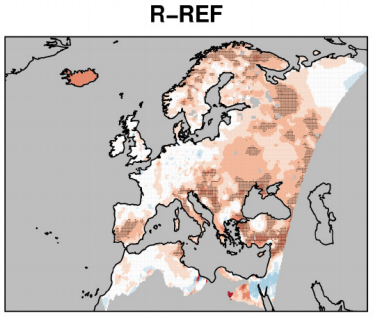

(a)

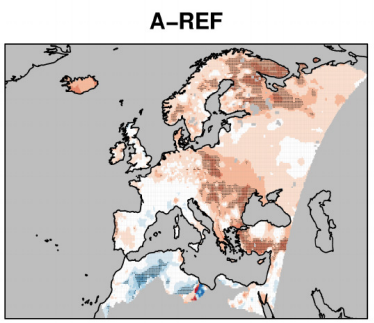

(d)

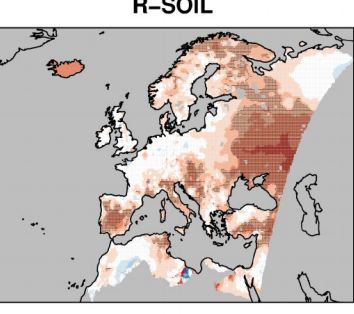

(b)

Corr.(R-SOIL) minus corr.(R-REF)

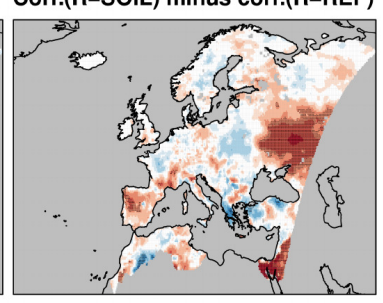

(c)

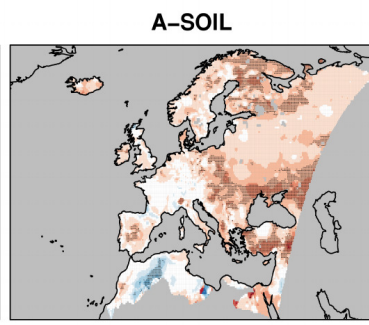

(e)

Corr.(A-SOIL) minus corr.(A-REF)

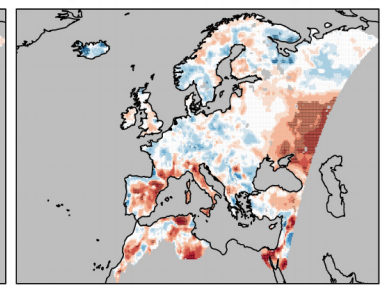

(f)

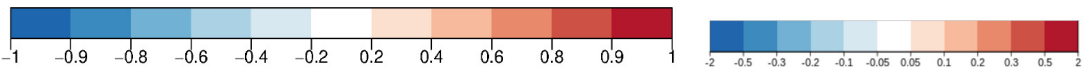

Fig. 5 JJA Tmin correlation with EOBS for (a) R-REF (b) R-SOIL (d) A-REF (e) A-SOIL and correlation differences R-SOIL minus R-REF (c) and A-SOIL minus A-REF (f) for experiments initialized 1st May 1993-2012. Stippling depicts values significantly different from 0 with a $95 \%$ confidence. 


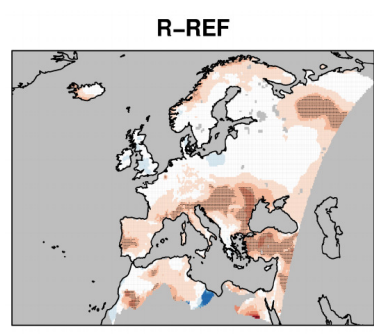

(a)

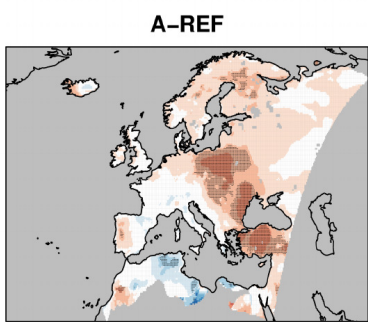

(d)

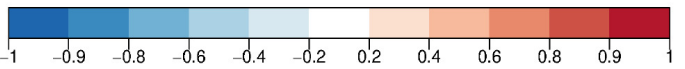

Fig. 6 Same as Fig. 5 for Tmax.
Corr.(R-SOIL) minus corr.(R-REF)

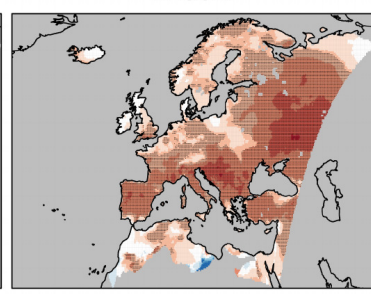

(b)

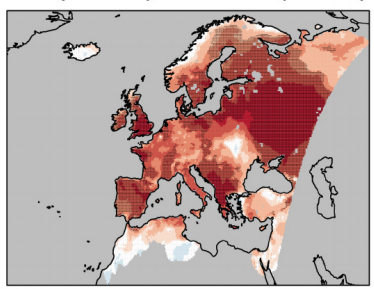

(c)

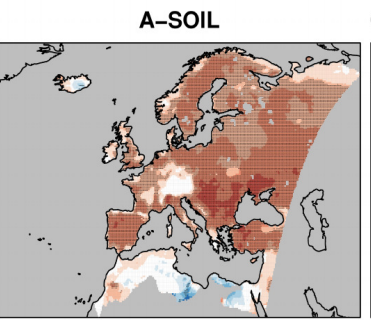

Corr.(A-SOIL) minus corr.(A-REF)

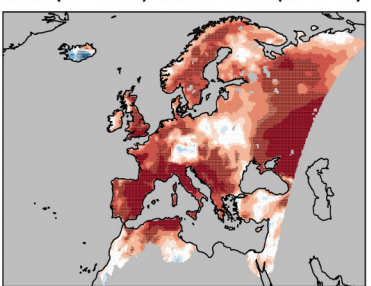

(f)

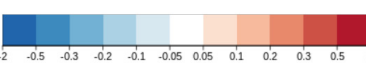




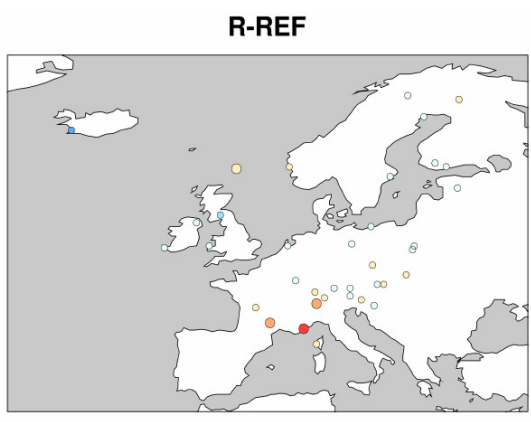

(a)

\section{A-REF}

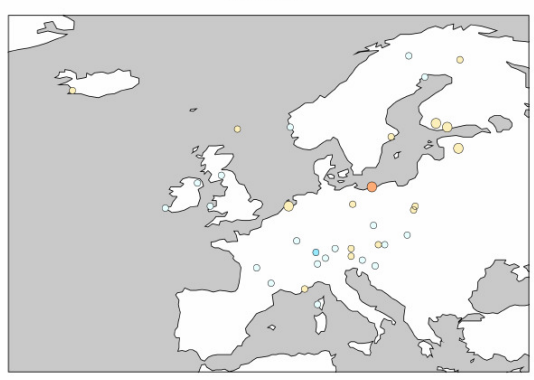

(c)
R-SOIL

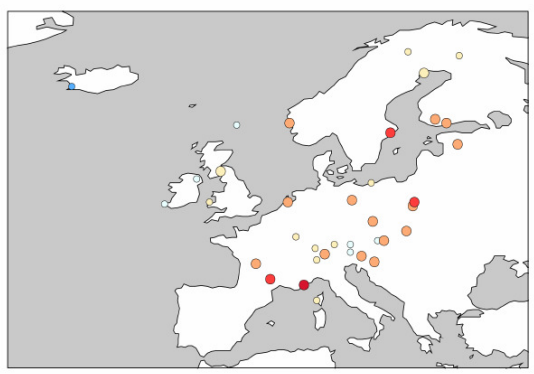

(b)

A-SOIL

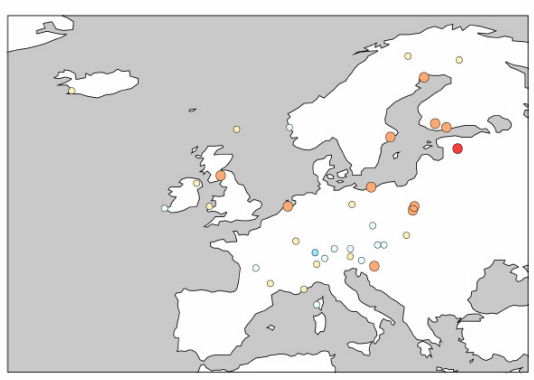

(d)

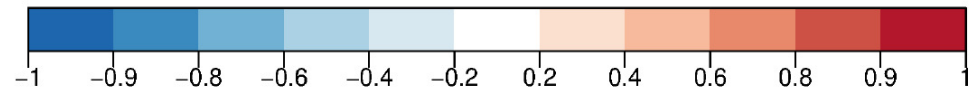

Fig. 7 JJA DSSR correlation with GEBA for (a) R-REF (b) R-SOIL (c) A-REF and (d) A-SOIL for experiments initialized 1st May 1993-2012. Large circles depict correlations significantly positive with a $95 \%$ confidence 


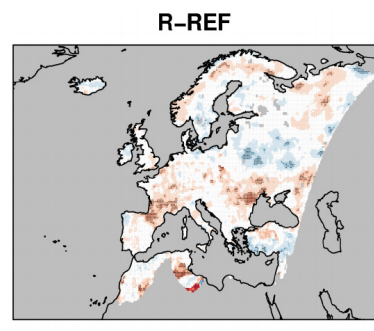

(a)

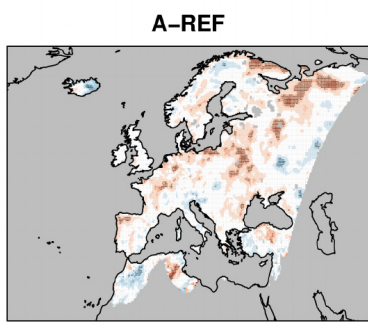

(d)

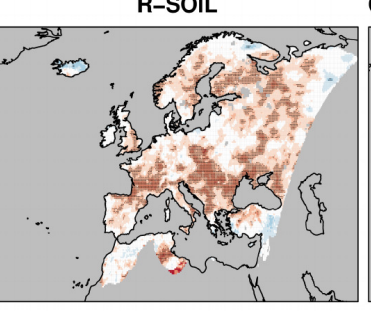

(b)

Corr.(R-SOIL) minus corr.(R-REF)

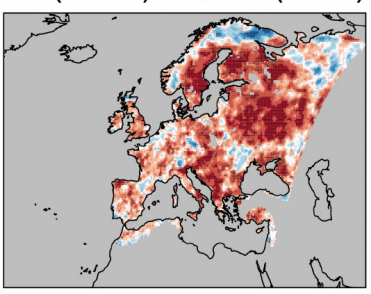

(c)

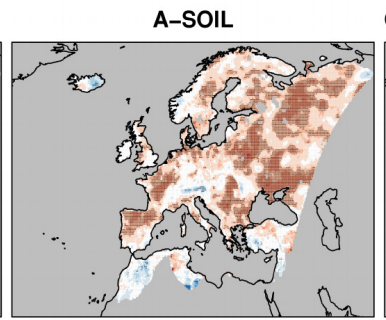

(e)

Corr.(A-SOIL) minus corr.(A-REF)

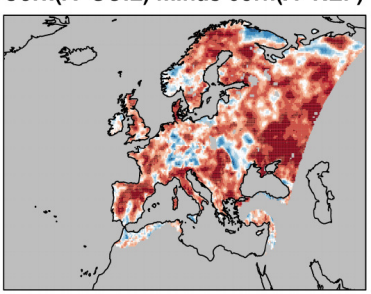

(f)
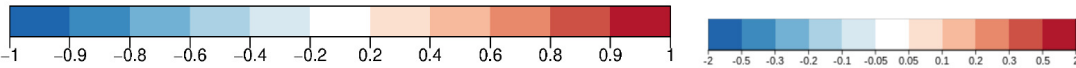

Fig. 8 Same as Fig. 5 for precipitation 


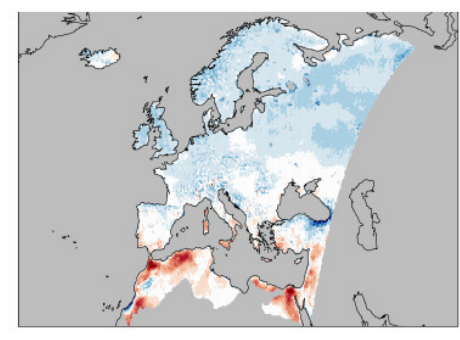

(a)

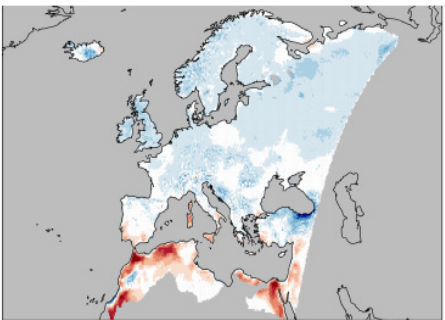

(c)

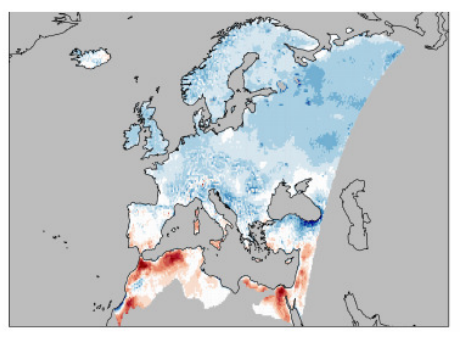

(b)

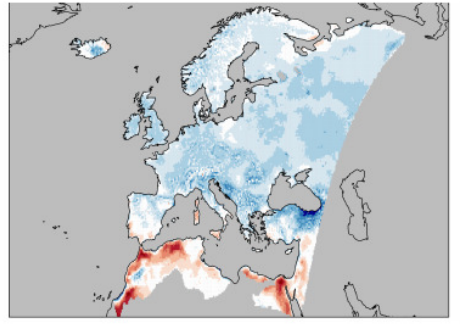

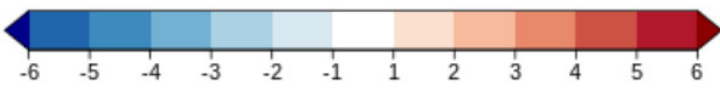

Fig. 9 JJA Tmax bias against EOBS in K for (a) R-REF (b) R-SOIL (c) A-REF and (d) A-SOIL for experiments initialized 1st May 1993-2012 


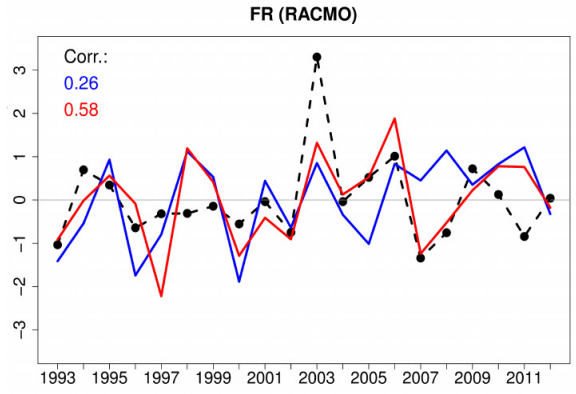

(a)

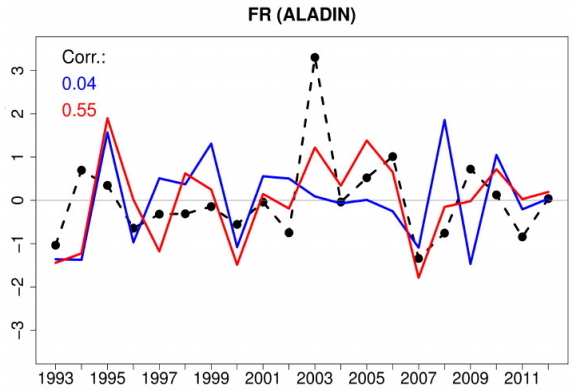

(c)

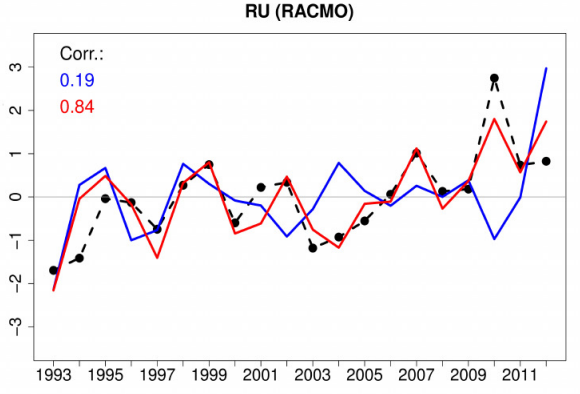

(b)

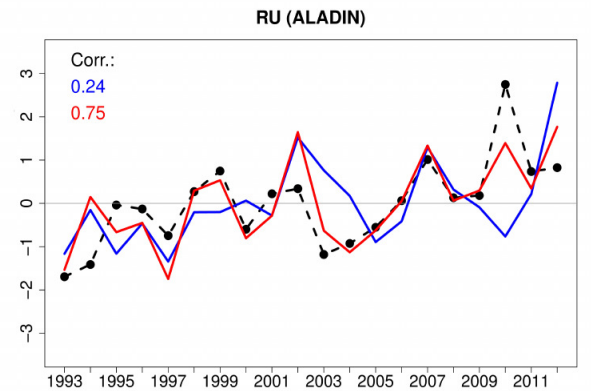

(d)

Fig. 10 Inter-annual JJA Tmax anomalies for FR (a) (c) and RU (b) (d). The first (second) row shows RACMO (ALADIN) experiments. The blue (red) solid line depicts REF (SOIL) ensemble mean and the black broken line the reference. Same colors are used to display the correlation values of corresponding experiments with the reference in the upper left corner 


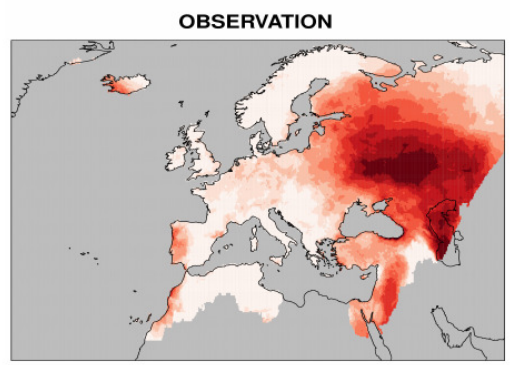

(a)

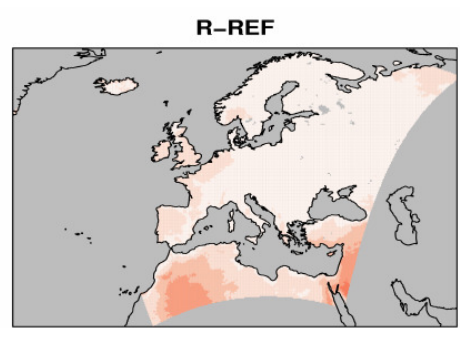

(b)

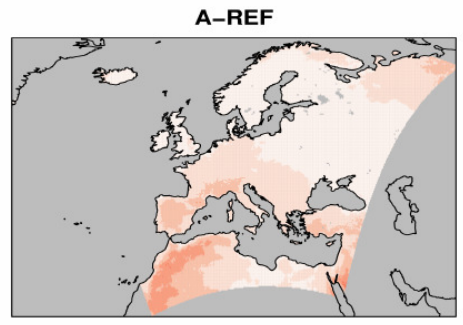

(d)

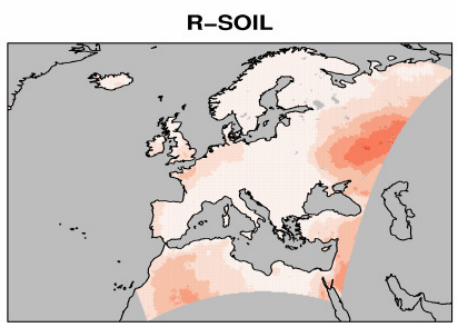

(c)

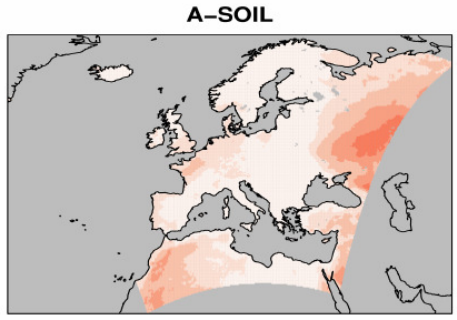

(e)

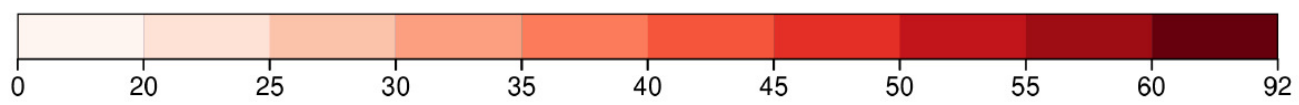

Fig. 11 Number of 2010 JJA hot days as defined in section 3.3 in (a) EOBS observation, (b) R-REF, (c) R-SOIL, (d) A-REF and (e) A-SOIL 


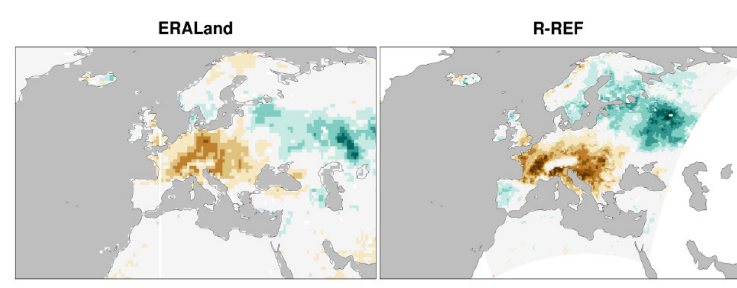

(a)

(b)

R-REF

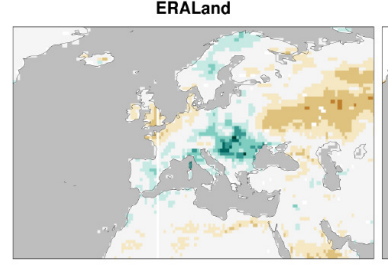

(d)

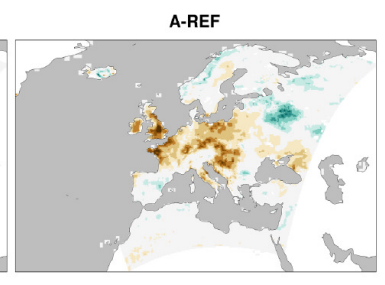

(c)

A-REF

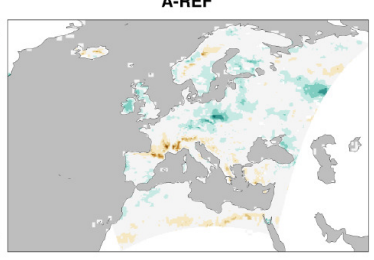

(f)

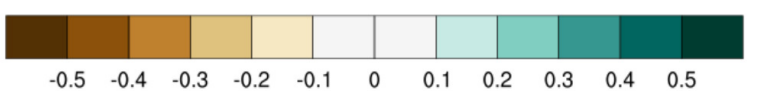

Fig. 12 JJA SMI anomaly: 2003 ERA-Land (a), R-REF (b), A-REF (c) and 2010 ERA-Land (d), R-REF (e) and A-REF (f) 
Table 1 Experiments summary

\begin{tabular}{cccc}
\hline Name & RCM & Soil moisture & Land Surface Model \\
\hline A-REF & ALADIN & Initialized & SURFEX 7.2 \\
A-SOIL & ALADIN & Daily nudged towards ERA-Land & SURFEX 7.2 \\
R-REF & RACMO & Initialized & HTESSEL \\
R-SOIL & RACMO & Daily replaced by ERA-Land & HTESSEL
\end{tabular}

Table 2 GCM ensemble simulation characteristics

\begin{tabular}{c|cc}
\hline & CNRM-CM & EC-Earth 3.1 \\
\hline Horizontal resolution & T1255 $(\sim 70 \mathrm{~km})$ & T255 $(\sim 70 \mathrm{~km})$ \\
Interactive ocean & Yes & No \\
Ensemble generation & Stochastic dynamics & Singular vectors \\
Land Surface Model & SURFEX 7.2 & HTESSEL \\
Land Surface initialization & Interpolated ERA-Land & ERA-Land \\
\hline
\end{tabular}

Table 3 Soil moisture index spread for RACMO (a) and ALADIN (b)

\begin{tabular}{c|ccc}
\hline & FR & RU & SW \\
\hline R-REF & 0.11 & 0.08 & 0.10 \\
R-SOIL & $8.1 \times 10^{-3}$ & $5.9 \times 10^{-3}$ & $8.9 \times 10^{-3}$ \\
Ratio R-SOIL/R-REF & $7.5 \%$ & $7.4 \%$ & $9.1 \%$
\end{tabular}

(a)

\begin{tabular}{c|ccc}
\hline & FR & RU & SW \\
\hline A-REF & 0.09 & 0.06 & 0.05 \\
A-SOIL & $8.6 \times 10^{-3}$ & $5.3 \times 10^{-3}$ & $5.9 \times 10^{-3}$ \\
Ratio A-SOIL/A-REF & $10.0 \%$ & $9.3 \%$ & $10.8 \%$
\end{tabular}

(b)

Table 4 Tmax spread for RACMO (a) and ALADIN (b)

\begin{tabular}{c|ccc}
\hline & FR & RU & SW \\
\hline R-REF & 3.91 & 3.27 & 3.28 \\
R-SOIL & 3.62 & 3.07 & 2.94 \\
Ratio R-SOIL/R-REF & $92.6 \%$ & $93.9 \%$ & $89.7 \%$
\end{tabular}

(a)

\begin{tabular}{c|ccc}
\hline & FR & RU & SW \\
\hline A-REF & 4.01 & 2.82 & 3.64 \\
A-SOIL & 3.25 & 2.75 & 2.74 \\
Ratio A-SOIL/A-REF & $81.1 \%$ & $97.4 \%$ & $75.2 \%$
\end{tabular}

(b) 
Table 5 Intra-annual (a) and inter-annual (b) variance ratio for Tmax, and ((c) and (d) respectively) for precipitation. Bold figures highlight significant differences between REF and SOIL experiments

\begin{tabular}{c|ccc}
\hline Tmax (intra) & FR & RU & SW \\
\hline R-REF/OBS & $\mathbf{1 . 3 7}$ & $\mathbf{0 . 9 7}$ & $\mathbf{1 . 0 2}$ \\
R-SOIL/OBS & $\mathbf{1 . 2 2}$ & $\mathbf{0 . 8 4}$ & $\mathbf{0 . 9 3}$ \\
\hline A-REF/OBS & $\mathbf{1 . 3 5}$ & $\mathbf{1 . 1 8}$ & 0.81 \\
A-SOIL/OBS & $\mathbf{0 . 9 1}$ & $\mathbf{0 . 7 2}$ & 0.81
\end{tabular}

(a)

\begin{tabular}{c|ccc}
\hline Tmax (inter) & FR & RU & SW \\
\hline R-REF/OBS & $\mathbf{1 . 4 7}$ & $\mathbf{0 . 5 5}$ & 0.72 \\
R-SOIL/OBS & $\mathbf{0 . 9 4}$ & $\mathbf{0 . 4 1}$ & 0.58 \\
\hline A-REF/OBS & $\mathbf{1 . 7 8}$ & $\mathbf{0 . 8 2}$ & 0.50 \\
A-SOIL/OBS & $\mathbf{0 . 6 2}$ & $\mathbf{0 . 4 3}$ & 0.42
\end{tabular}

(b)

\begin{tabular}{c|ccc}
\hline Pr (intra) & FR & RU & SW \\
\hline R-REF/OBS & 1.09 & $\mathbf{0 . 9 1}$ & 0.99 \\
R-SOIL/OBS & 1.11 & $\mathbf{1 . 0 4}$ & 1.00 \\
\hline A-REF/OBS & $\mathbf{1 . 0 4}$ & $\mathbf{0 . 7 2}$ & 1.01 \\
A-SOIL/OBS & $\mathbf{1 . 2 8}$ & $\mathbf{0 . 9 8}$ & 1.05
\end{tabular}

(c)

\begin{tabular}{c|ccc}
\hline Pr (inter) & FR & RU & SW \\
\hline R-REF/OBS & 1.65 & 0.95 & 0.88 \\
R-SOIL/OBS & 1.42 & 0.75 & 0.87 \\
\hline A-REF/OBS & $\mathbf{2 . 0 7}$ & $\mathbf{1 . 3 3}$ & 1.02 \\
A-SOIL/OBS & $\mathbf{1 . 5 6}$ & $\mathbf{1 . 0 3}$ & 0.91
\end{tabular}

(d) 


\section{References}

Albergel C, Balsamo G, de Rosnay P, Muñoz-Sabater J, Boussetta S (2012) A bare ground evaporation revision in the ECMWF land-surface scheme: evaluation of its impact using ground soil moisture and satellite microwave data. Hydrology and Earth System Sciences 16(10):3607-3620

Ardilouze C, Batté L, Bunzel F, Decremer D, Déqué M, Doblas-Reyes F, Douville H, Fereday D, Guemas V, MacLachlan C, Müller W, Prodhomme C (2017) Multimodel assessment of the impact of soil moisture initialization on mid-latitude summer predictability. Climate Dynamics 49(11-12):3959-3974

Balsamo G, Beljaars A, Scipal K, Viterbo P, van den Hurk B, Hirschi M, Betts AK (2009) A Revised Hydrology for the ECMWF Model: Verification from Field Site to Terrestrial Water Storage and Impact in the Integrated Forecast System. Journal of Hydrometeorology 10(3):623-643

Balsamo G, Albergel C, Beljaars A, Boussetta S, Brun E, Cloke H, Dee D, Dutra E, Muñoz-Sabater J, Pappenberger F, et al (2015) Era-Interim/Land: a global land surface reanalysis data set. Hydrology and Earth System Sciences 19(1):389-407, doi:10.5194/hess-19-389-2015

Batté L, Ardilouze C, Déqué M (2018) Forecasting west african heat waves at subseasonal and seasonal time scales. Monthly Weather Review DOI 10.1175/MWRD-17-0211.1

Betts AK (2004) Understanding Hydrometeorology Using Global Models. Bulletin of the American Meteorological Society 85(11):1673-1688,

Boisserie M, Decharme B, Descamps L, Arbogast P (2016) Land surface initialization strategy for a global reforecast dataset. Quarterly Journal of the Royal Meteorological Society 142(695):880-888

Brier GW (1950) Verification of forecasts expressed in terms of probability. Monthly weather review 78(1):1-3

Bunzel F, Müller WA, Dobrynin M, Fröhlich K, Hagemann S, Pohlmann H, Stacke T, Baehr J (2018) Improved seasonal prediction of european summer temperatures with new five-layer soil-hydrology scheme. Geophysical Research Letters 45(1):346-353

Buontempo C, Hewitt CD, Doblas-Reyes FJ, Dessai S (2014) Climate service development, delivery and use in europe at monthly to inter-annual timescales. Climate Risk Management 6:1-5

Colin J, Déqué M, Radu R, Somot S (2010) Sensitivity study of heavy precipitation in Limited Area Model climate simulations: influence of the size of the domain and the use of the spectral nudging technique. Tellus A 62(5):591-604

Decharme B, Boone A, Delire C, Noilhan J (2011) Local evaluation of the interaction between soil biosphere atmosphere soil multilayer diffusion scheme using four pedotransfer functions. Journal of Geophysical Research: Atmospheres 116(D20)

Dee DP, Uppala SM, Simmons AJ, Berrisford P, Poli P, Kobayashi S, Andrae U, Balmaseda MA, Balsamo G, Bauer P, Bechtold P, Beljaars ACM, van de Berg L, Bidlot J, Bormann N, Delsol C, Dragani R, Fuentes M, Geer AJ, Haimberger L, Healy SB, Hersbach H, Hólm EV, Isaksen L, Kållberg P, Köhler M, Matricardi M, McNally AP, Monge-Sanz BM, Morcrette JJ, Park BK, Peubey C, de Rosnay 
P, Tavolato C, Thépaut JN, Vitart F (2011) The ERA-Interim reanalysis: configuration and performance of the data assimilation system. Quarterly Journal of the Royal Meteorological Society 137(656):553-597,

Dirmeyer PA (2011) The terrestrial segment of soil moisture-climate coupling. Geophysical Research Letters 38(16)

Doblas-Reyes FJ, Déqué M, Piedelievre JP (2000) Multi-model spread and probabilistic seasonal forecasts in PROVOST. Quarterly Journal of the Royal Meteorological Society 126(567):2069-2087

Doblas-Reyes FJ, García-Serrano J, Lienert F, Biescas AP, Rodrigues LR (2013) Seasonal climate predictability and forecasting: status and prospects. Wiley Interdisciplinary Reviews: Climate Change 4(4):245-268

Douville H (2003) Assessing the influence of soil moisture on seasonal climate variability with AGCMs. Journal of Hydrometeorology 4(6):1044-1066

Douville H, Colin J, Krug E, Cattiaux J, Thao S (2016) Midlatitude daily summer temperatures reshaped by soil moisture under climate change. Geophysical Research Letters 43(2):812-818

Feudale L, Shukla J (2011) Influence of sea surface temperature on the european heat wave of 2003 summer. part ii: a modeling study. Climate Dynamics 36(910):1705-1715

Field CB, Barros VR (2014) Climate change 2014: impacts, adaptation, and vulnerability, vol 1

Fischer EM, Seneviratne S, Vidale P, Lüthi D, Schär C (2007) Soil moistureatmosphere interactions during the 2003 European summer heat wave. Journal of Climate 20(20):5081-5099

Flato G, Marotzke J, Abiodun B, Braconnot P, Chou SC, Collins WJ, Cox P, Driouech F, Emori S, Eyring V, et al (2013) Evaluation of Climate Models. In: Climate Change 2013: The Physical Science Basis. Contribution of Working Group I to the Fifth Assessment Report of the Intergovernmental Panel on Climate Change. Climate Change 2013 5:741-866

Guillod BP, Orlowsky B, Miralles DG, Teuling AJ, Seneviratne SI (2015) Reconciling spatial and temporal soil moisture effects on afternoon rainfall. Nature communications 6:6443

Hauser M, Orth R, Seneviratne SI (2016) Role of soil moisture versus recent climate change for the 2010 heat wave in western russia. Geophysical Research Letters 43(6):2819-2826

Haylock M, Hofstra N, Klein Tank A, Klok E, Jones P, New M (2008) A european daily high-resolution gridded data set of surface temperature and precipitation for 1950-2006. Journal of Geophysical Research: Atmospheres 113(D20)

Hazeleger W, Severijns C, Semmler T, Ştefănescu S, Yang S, Wang X, Wyser K, Dutra E, Baldasano JM, Bintanja R, et al (2010) EC-Earth: a seamless earth-system prediction approach in action. Bulletin of the American Meteorological Society 91(10):1357-1363

van den Hurk B, Doblas-Reyes F, Balsamo G, Koster RD, Seneviratne SI, Camargo H (2012) Soil moisture effects on seasonal temperature and precipitation forecast scores in Europe. Climate Dynamics 38(1-2):349-362, 
Knist S, Goergen K, Buonomo E, Christensen OB, Colette A, Cardoso RM, Fealy R, Fernández J, García-Díez M, Jacob D, et al (2017) Land-atmosphere coupling in EURO-CORDEX evaluation experiments. Journal of Geophysical Research: Atmospheres 122(1):79-103

Koster RD, Dirmeyer PA, Guo Z, Bonan G, Chan E, Cox P, Gordon C, Kanae S, Kowalczyk E, Lawrence D, et al (2004) Regions of strong coupling between soil moisture and precipitation. Science 305(5687):1138-1140

Manzanas R, Gutiérrez J, Fernández J, van Meijgaard E, Calmanti S, Magariño M, Cofiño A, Herrera S (2017) Dynamical and statistical downscaling of seasonal temperature forecasts in Europe: Added value for user applications. Climate Services. doi:10.1016/j.cliser.2017.06.004

Masson V, Le Moigne P, Martin E, Faroux S, Alias A, Alkama R, Belamari S, Barbu A, Boone A, Bouyssel F, Brousseau P, Brun E, Calvet JC, Carrer D, Decharme B, Delire C, Donier S, Essaouini K, Gibelin AL, Giordani H, Habets F, Jidane M, Kerdraon G, Kourzeneva E, Lafaysse M, Lafont S, Lebeaupin Brossier C, Lemonsu A, Mahfouf JF, Marguinaud P, Mokhtari M, Morin S, Pigeon G, Salgado R, Seity Y, Taillefer F, Tanguy G, Tulet P, Vincendon B, Vionnet V, Voldoire A (2013) The SURFEXv7.2 land and ocean surface platform for coupled or offline simulation of earth surface variables and fluxes. Geoscientific Model Development 6(4):929-960

Miralles DG, Teuling AJ, Van Heerwaarden CC, de Arellano JVG (2014) Megaheatwave temperatures due to combined soil desiccation and atmospheric heat accumulation. Nature geoscience 7(5):345-349

Mueller B, Seneviratne SI (2012) Hot days induced by precipitation deficits at the global scale. Proceedings of the national academy of sciences 109(31):1239812403

Murphy AH (1973) A new vector partition of the probability score. Journal of Applied Meteorology 12(4):595-600

Novick K, Oren R, Stoy P, Siqueira M, Katul G (2009) Nocturnal evapotranspiration in eddy-covariance records from three co-located ecosystems in the Southeastern US: implications for annual fluxes. Agricultural and Forest Meteorology 149(9):1491-1504

Orth R, Seneviratne SI (2017) Variability of soil moisture and sea surface temperatures similarly important for warm-season land climate in the community earth system model. Journal of Climate 30(6):2141-2162

Palmer T, Branković Č, Richardson D (2000) A probability and decision-model analysis of provost seasonal multi-model ensemble integrations. Quarterly Journal of the Royal Meteorological Society 126(567):2013-2033

Prodhomme C, Doblas-Reyes F, Bellprat O, Dutra E (2016) Impact of land-surface initialization on sub-seasonal to seasonal forecasts over Europe. Climate dynamics 47(3-4):919-935

Quesada B, Vautard R, Yiou P, Hirschi M, Seneviratne SI (2012) Asymmetric European summer heat predictability from wet and dry southern winters and springs. Nature Climate Change 2(10):736

Reichle RH, Koster RD, De Lannoy GJ, Forman BA, Liu Q, Mahanama SP, Touré A (2011) Assessment and enhancement of MERRA land surface hydrology estimates. Journal of Climate 24(24):6322-6338 
Rodwell M, Doblas-Reyes F (2006) Medium-Range, monthly, and seasonal prediction for Europe and the use of forecast information. Journal of Climate 19:60256046

Roudier P, Andersson JC, Donnelly C, Feyen L, Greuell W, Ludwig F (2016) Projections of future floods and hydrological droughts in europe under a+ $2 \mathrm{c}$ global warming. Climatic change 135(2):341-355

Sanchez-Lorenzo A, Wild M, Brunetti M, Guijarro JA, Hakuba MZ, Calbó J, Mystakidis S, Bartok B (2015) Reassessment and update of long-term trends in downward surface shortwave radiation over Europe (1939-2012). Journal of Geophysical Research: Atmospheres 120(18):9555-9569

Schär C, Lüthi D, Beyerle U, Heise E (1999) The SoilPrecipitation Feedback: A Process Study with a Regional Climate Model. Journal of Climate 12(3):722-741

Seneviratne SI, Koster RD (2012) A revised framework for analyzing soil moisture memory in climate data: Derivation and interpretation. Journal of Hydrometeorology 13(1):404-412

Seneviratne SI, Koster RD, Guo Z, Dirmeyer PA, Kowalczyk E, Lawrence D, Liu P, Lu CH, Mocko D, Oleson KW, Verseghy D (2006) Soil moisture memory in AGCM simulations: Analysis of global land-atmosphere coupling experiment (GLACE) data. Journal of Hydrometeorology 7(5):1090-1112

Seneviratne SI, Corti T, Davin EL, Hirschi M, Jaeger EB, Lehner I, Orlowsky B, Teuling AJ (2010) Investigating soil moisture-climate interactions in a changing climate: A review. DOI 10.1016/j.earscirev.2010.02.004, Web of Science

Sheffield J, Wood EF (2007) Characteristics of global and regional drought, 19502000: Analysis of soil moisture data from off-line simulation of the terrestrial hydrologic cycle. Journal of Geophysical Research: Atmospheres 112(D17)

Siegert S, Bellprat O, Ménégoz M, Stephenson DB, Doblas-Reyes FJ (2017) Detecting improvements in forecast correlation skill: Statistical testing and power analysis. Monthly Weather Review 145(2):437-450

Tolk JA, Howell TA, Evett SR (2006) Nighttime evapotranspiration from alfalfa and cotton in a semiarid climate. Agronomy journal 98(3):730-736

Van Meijgaard E, Van Ulft L, Lenderink G, De Roode S, Wipfler EL, Boers R, van Timmermans R (2012) Refinement and application of a regional atmospheric model for climate scenario calculations of Western Europe. KVR 054/12, KVR, 44pp. http://climexp.knmi.nl/publications/FinalReport_KvR-CS06.pdf

Vautard R, Gobiet A, Sobolowski S, Kjellström E, Stegehuis A, Watkiss P, Mendlik T, Landgren O, Nikulin G, Teichmann C, et al (2014) The european climate under a 2 c global warming. Environmental Research Letters 9(3):034006

Voldoire A, Sanchez-Gomez E, Salas y Mélia D, Decharme B, Cassou C, Sénési S, Valcke S, Beau I, Alias A, Chevallier M, et al (2013) The CNRM-CM5. 1 global climate model: description and basic evaluation. Climate Dynamics 40(910):2091-2121

Weisheimer A, Doblas-Reyes FJ, Jung T, Palmer T (2011) On the predictability of the extreme summer 2003 over Europe. Geophysical Research Letters 38(5)

Zampieri M, DAndrea F, Vautard R, Ciais P, de Noblet-Ducoudré N, Yiou P (2009) Hot European summers and the role of soil moisture in the propagation of Mediterranean drought. Journal of Climate 22(18):4747-4758 
715 Zou GY (2007) Toward using confidence intervals to compare correlations. Psycho$716 \quad$ logical methods 12(4):399 